\title{
Humming as a means of communicating during mealtime situations: A single case study involving a woman with severe dementia and her caregiver
}

\author{
Lena Marmstål Hammar¹, Christine Williams², Anna Swall' ${ }^{3}$, Gabriella Engström \\ 1. School of Health, Malardalen University, Sweden. 2. Florida Atlantic University, United States. 3. Division of Nursing, \\ Sophiahemmet Collage University, Sweden.
}

Correspondence: Lena Marmstal Hammar. Address: School of Health, Care and Social Welfare, Mälardalen University, Sweden. Email: lena.marmstal.hammar@mdh.se

Received: December 21, $2011 \quad$ Accepted: March 21, $2012 \quad$ Published: August 1, 2012

DOI : 10.5430/jnep.v2n3p93 URL: http://dx.doi.org/10.5430/jnep.v2n3p93

\section{Abstract}

Objective: 'Music Therapeutic Caregiving', when caregivers sing for or together with persons with dementia during morning care situations, has been shown to increase verbal and nonverbal communication between persons with dementia and their caregivers, as well as enhance positive and decrease negative emotions in persons with dementia. No studies about singing during mealtimes have been conducted, and this pilot project was designed to elucidate this. However, since previous studies have shown that there is a risk that persons with dementia will start to sing along with the caregiver, the caregiver in this study hummed such that the person with dementia did not sing instead of eat. The aim of this pilot project was threefold: to describe expressed emotions in a woman with severe dementia, and describe communication between her and her caregivers without and with the caregiver humming. The aim was also to measure food and liquid intake without and with humming.

Method: The study was constructed as a Single Case ABA design in which the ordinary mealtime constituted a baseline which comprised a woman with severe dementia being fed by her caregivers in the usual way. The intervention included the same woman being fed by the same caregiver who hummed while feeding her. Data comprised video observations that were collected once per week over 5 consecutive weeks. The Verbal and Nonverbal Interaction Scale and Observed Emotion Rating Scale were used to analyze the recorded interactions.

Results: A slightly positive influence of communication was shown for the woman with dementia, as well as for the caregiver. Further, the women with dementia showed a slight increase in expressions of positive emotions, and she ate more during the intervention.

Conclusion: Based on this pilot study no general conclusions can be drawn. It can be concluded, however, that humming while feeding persons with dementia might slightly enhance communication, and positive expressed emotions in persons with dementia. To confirm this, more studies on group levels are needed. Because previous studies have found that caregiver singing during caring situations influences persons with dementia positively it might be desirable to test the same during mealtime. 


\section{Key words}

Caregiver, Dementia, Eating, Intervention, Singing, Humming, Single case, Communication, Emotion

\section{I ntroduction}

Persons with dementia suffer from major cognitive impairment in meeting universal self-care needs, which can include maintaining a sufficient intake of fluids and food ${ }^{[1,2]}$. Because of cognitive impairments and physical and sensory disabilities, eating needs can go unmet ${ }^{[3]}$. Eating by oneself is a complex process requiring organizational, conceptual and physical skills which persons with dementia may no longer have ${ }^{[2]}$. It is thereby common that persons with dementia are fed meals. Often persons with dementia do not perceive the caregiver as helpful when feeding assistance is provided and the caregivers experience difficulty providing feeding assistance, according to Change and Roberts ${ }^{[4]}$. Feeding is crucial to prevent starvation of persons with dementia, and the problems addressed to the feeding activities needs to be utilized. O'Connor, Ames, Gardner, and King ${ }^{[4]}$ emphasize that persons with dementia have difficulties in expressing and interpreting verbal and non-verbal communication, and this is a common obstruction in communication with the caregivers. Hanson, Carey, Caprio et al. ${ }^{[5]}$ argue that communication difficulties are a serious obstruction even during mealtime, especially when persons with dementia are being fed.

Several strategies have been investigated in an attempt to facilitate communication during complex caring situations. Small, Perry and Lewis ${ }^{[6]}$ suggested that caregivers' psychosocial behaviors to be acknowledged to better communicate with persons with dementia and Vasse and collegues ${ }^{[7]}$ suggested that non-pharmacological interventions, such as single-task converasation or one to one conversation was to prefer. Studies of communication generally frame the issue in terms of verbal communication; e.g. Azuma and Bayles ${ }^{[8]}$ note that caregivers should speak slowly and in short sentences, ask closed-ended questions, and talk about concrete matters, while Small, et. al ${ }^{[9]}$ argue that slower speech is ineffective because Persons with dementia forget the earlier part of the utterance. They further suggest that questions should be asked in a manner that limits demands, and that caregivers should encourage persons with dementia with their speech. Christenson, Buchanan, Houlihan, and Wanzek ${ }^{[10]}$ recommend using 'alpha commands', which are commands that are clear, concise and feasible and will make persons with dementia more likely to comply during caring activities. Williams and Herman ${ }^{[11]}$ propose that caregivers should use an emotional tone of voice that is caring and respectful, and therewith decrease expressions of resistance during caring. None of these groups elucidate non-verbal communication. Persons with dementia commonly express verbal as well as non-verbal communication through emotions. These emotions might be negative, such as sadness or anger, but can also be positive such as pleasure or being generally alert in their communication with caregivers during complex dementia care situations ${ }^{[12]}$. Research about communication and persons with dementia' expressed emotions in the context of the complex dementia care situation of feeding is lacking.

Music has been shown to have a positive influence on persons with dementia during music therapy and during music listening ${ }^{[13,14]}$, and during mealtime music listening has seemed to improve appetite ${ }^{[15]}$. Studies that have focused on morning care situations have shown that when the caregiver sings for or together with persons with dementia, so called Music Therapeutic caregiving [MTC] ${ }^{[16]}$, the persons with dementia appear relaxed ${ }^{[15,17-19]}$, self-confident ${ }^{[17,18,20]}$, and are more active during the caring activity ${ }^{[19,21]}$. It has also been shown that persons with dementia' communication is enhanced ${ }^{[22,23]}$, and communication and cooperation between persons with dementia and caregivers is easier to achieve ${ }^{[22,23]}$. The positive effects of MTC would be desirable to implement during mealtime situations with persons with dementia. However, since previous studies have found that persons with dementia commonly start to sing when caregivers are singing, the use of MTC was associated with the risk that the person with dementia would start to sing instead of eat. Since it might be the lyrics of songs sung by the caregiver during MTC that led the persons with dementia to sing, this study was designed so that the caregiver hummed songs only and thus excluded lyrics. To elucidate how humming might influence mealtime situations between persons with dementia and their caregivers this pilot project was designed to include a woman with severe dementia being fed by her caregivers. The aim was to describe expressed emotions in a 
woman with severe dementia and communication between her and her caregiver without and with the caregiver humming. The aim was also to measure food and liquid intake without and with humming.

\section{Method}

\subsection{Design and settings}

We conducted this study using a single case experimental ABA design ${ }^{[24]}$. 'A' represents the baseline condition, 'B' refers to intervention administration and the second ' $A$ ' represents a return to the baseline condition (follow up). The participants, one person, Mrs. Andersson (fictitious name) with severe dementia, and her caregiver, were recruited from a nursing home in Sweden. The participating person with dementia was included in the pilot study since she met the inclusion criteria of having severe dementia, which was calculated by elucidating cognitive functions with the Mini Mental State Examination (MMSE) ${ }^{[25]}$. Severe dementia is indicated with a score of $<12$. This person with dementia scored 0 . A further criterion was that the candidate was unable to eat by herself and had been living in a nursing home for at least one year prior to the start of the study. An inclusion criterion for the caregiver was that she should have been a caregiver for Mrs. Andersson for at least three months. The caregiver was informed about the aims of the study including procedure and conditions for inclusion. Voluntary participation and confidentiality was assured.

Data for this study were collected by video observations of Mrs. Andersson and her caregiver during the lunch service, the lunch was served at noon each day. All lunch situations occurred in Mrs. Andersson's private room at the ward, with her sitting in her bed. No changes in Mrs. Andersson's environment occurred during the data collection. During all video observations, the caregiver sat on a chair facing Mrs. Andersson. During the whole lunch situation, the caregiver held the lunch plate in one of her hands, giving Mrs. Andersson the ability to see and smell the lunch. A beverage in a glass was placed on a table and was easy to reach for the caregiver.

Data were collected once per week over 5 consecutive weeks. The first 2 recordings consisted of a normal lunch situation when the caregiver fed Mrs. Andersson. For the next two weeks the caregiver was instructed to hum sing-along songs, children's songs and popular songs from the early part of the 20th century for Mrs. Andersson while she was feeding her. As previously stated, the caregiver was instructed to hum songs only and refrain from singing, because earlier studies conducted by Hammar Marmstål, Emami, Engström and Götell ${ }^{[18,23,26]}$, and Hammar Marmstål, Emami, Götell and Engström ${ }^{[19]}$, as well as Engström, Hammar Marmstål, Williams and Götell ${ }^{[22,27]}$ have shown that persons with severe dementia sometimes start to sing with their caregivers during caring situations. It was important that Mrs. Andersson could concentrate on eating rather than singing during the lunch service. Finally, during the last week of video observation Mrs. Andersson and the caregiver returned to a normal lunch situation without humming. The first two normal lunch situations lasted for 22 and 19 minutes respectively. The recordings consisted with the caregiver humming lasted for 21 and 15 minutes and finally the last mealtime observation lasted for 13 minutes.

Analysis of video observations were conducted with the Verbal and Nonverbal Interaction scale [VNVIS] developed by Williams and Parker ${ }^{[28]}$ and with the Observed Emotion Rating Scale ${ }^{[29,30]}$. All five video observations covered the entire lunch situation, but since the instrument was to be used to analyze the occurrence of verbal and nonverbal communication behaviors over a ten minute period only the first ten minutes of the recordings have been analyzed. However, liquid and food intake for Mrs. Andersson were included as data, and therefore the caregiver was instructed to measure the food and liquid prior to and after all lunch services in their full length, and not only after ten minutes. The food at the nursing home was pre ordered for every person living there, and relatives to Mrs. Andersson had done this order based on what they thought she would like to eat. This was a normal routine at the nursing home, and thus no extraordinary food was ordered for this study. The caregiver was also instructed report changes in Mrs. Andersson's status or other observations not included in the Verbal and Nonverbal Interaction scale. 


\subsection{The participant}

Mrs. Andersson, aged 87, had been living at the nursing home for 16 years. According to her medical records, she was diagnosed with Alzheimer's disease with a Mini Mental Examination (MMSE) (Folstein 1975) at the baseline of zero. The caregiver was female and aged 51, was an educated assistant nurse, and had been working in dementia care for 31 years and at the nursing home for almost six years.

\subsection{The instrument}

The Verbal-Nonverbal Interaction Scale ${ }^{[28]}$ is an observational measure of verbal and nonverbal communication between a caregiver and care receiver with dementia. Part one of the measure is for rating caregiver communication. In part two, the data collector rates the care receiver communication. The procedure is based on a 10 minute segment of videotaped interaction in which the rater reviews the videotape as many times as necessary to complete the scoring of each specific verbal or nonverbal communication behavior in one minute intervals for a total of 10 minutes. One set of items applies to the caregiver and another to the care receiver. Each item is scored 1 if the behavior occurred at least once in a one minute time frame and 0 if the behavior did not occur. A total score ranging from 0 to 10 is obtained by adding the scores. This procedure is repeated until all ten-one minute segments are scored. Reliability and validity was supported in a previous study of individuals with Alzheimer's disease and their spouse caregivers ${ }^{[27,28]}$.

Observed Emotion Rating Scale (OERS) ${ }^{[29,30]}$ is a five point scale measuring facially expressed emotions for persons with dementia. The reliability of the scale ranged from .76 to $.89^{[30]}$. The scale is divided into two positively expressed emotions (pleasure and general alertness) and three negatively expressed emotions (anger, anxiety/fear, and sadness). Each item is rated on a five-point duration scale: not in view, never, less than 16 seconds, 16-59 seconds, 1-5 minutes, and more than 5 minutes.

\subsection{Ethical considerations}

All consent and data collection procedures were approved by the Regional Board of Research Ethics (nr: 4.1-82/2008). Since Mrs. Andersson was diagnosed with severe dementia, she was unable to understand the purpose of the research. Therefore Mrs. Andersson's next of kin were informed about the aims of the study in writing and orally. Mrs. Andersson's next of kin understood the purpose of the study and that they were able to withdraw from the study without penalty if they so wished. Because Mrs. Andersson has severe dementia, ethical considerations with respect to self-determination and personal privacy are very important when collecting data by videotaping. During the videotaping the researcher carefully observed Mrs. Andersson for any signs that indicated that she objected to participating in the study or that her integrity was being compromised.

\section{Results}

The mean intake of food increased during the intervention. During the baseline, Mrs. Andersson's mean intake of food was 125 grams while during the intervention the mean intake of food was 200 gr. At the follow up, Mrs. Andersson's intake of food was 82 gr. The mean intake of liquid was observed to increase by 107\%, from a mean intake of 100 milliliters during baseline sessions to 207 milliliters during humming intervention sessions. At the follow up, the intake of liquid was even lower than during baseline (63 milliliters). The caregiver was instructed to observe changes in Mrs. Andersson's status not related to the interaction scale; however no changes were reported or observed on the video observations.

Verbal and nonverbal communications for Mrs. Andersson were measured with the Verbal and Nonverbal Interaction scale. The sociable nonverbal variable "calm - relaxed" was expressed equally by Mrs. Andersson during baseline, intervention and follow up observations. Mrs. Andersson's ability to "look at the caregiver "differed between the observations. During the first baseline observation, Mrs. Andersson looked at the caregiver in six of the ten minutes measured. The ability to look at the caregiver decreased and both during the second baseline and during both interventions 
she looked at the caregiver only once or twice. The variable "appears interested" occurred only during the intervention observations. During the interventions, Mrs. Andersson was focused on the caregiver and on the food. She was alert and opened her mouth long before the caregiver reached her mouth with the food (see Table 1).

Table 1. Verbal and Nonverbal Interaction of Mrs Andersson during two Baseline, two Intervention sessions and one Follow up session (Total score 0-10).

\begin{tabular}{llllll}
\hline & \multicolumn{2}{c}{ Care Recipient } & \\
\hline & Baseline 1 & Baseline 2 & Intervention 1 & Intervention 2 & Follow up \\
\hline Calm relaxed & 10 & 10 & 10 & 10 & 10 \\
Look at partner & 6 & 2 & 2 & 1 & 0 \\
Appears interested & 0 & 0 & 3 & 2 & 0 \\
Stares into space & 10 & 10 & 2 & 2 & 2 \\
Does not respond to question & 6 & 2 & 0 & 0 & 0 \\
Argumentative & 1 & 0 & 0 & 0 & 0 \\
Rejecting & 6 & 0 & 0 & 0 & 0 \\
Verbalizes negative affection & 2 & 0 & 2 & 2 & 0 \\
Humming & 0 & 0 & &
\end{tabular}

The most frequently observed unsociable nonverbal communication under the baseline condition was "stared into space". During the interventions, Mrs. Andersson continued to not make eye contact or look at the caregiver but not to the same extent as during baseline. During follow up, Mrs. Andersson had her eyes closed because she appeared to be resting. The unsociable nonverbal variable "does not respond to questions" was observed during all observations. Even if the caregiver asked simple questions and just asked one question at a time such as, "Do you want more?”, "Is it hot?”, or “Do you want a drink?”. Mrs. Andersson did not have the ability to respond verbally or nonverbally to the questions. The three variables "argumentative", "rejecting” and "verbalizes negative affection" was only expressed by Mrs. Andersson during baseline observations.

No sociable verbal communication was expressed during the baseline observations. During the intervention when the caregiver was humming one very popular song from the early part of the 20th century, Mrs. Andersson started to express incomprehensible sounds without tact and tone. However, since this sound was relevant to the situation we interpret this sound as an indication that Mrs. Andersson was humming together with the caregiver. This was the only time Mrs. Andersson responded to the caregiver's communication.

Table 2. Duration of Mrs. Andersson's expressed emotions of the OERS

\begin{tabular}{llllll}
\hline & & \multicolumn{2}{c}{ Emotional rating scale } & & \\
\hline & Baseline 1 & Baseline 2 & Intervention 1 & Intervention 2 & Follow up \\
\hline Pleasure & Never & Never & Never & Never & Never \\
Anger & Never & Never & Never & Never & Never \\
Anxiety/Fear & Less than 16 sec & Never & Never & Never & Never \\
Sadness & Never & Never & Never & Never & Never \\
General alertness & Less than 16 sec & Never & 16-59 sec & Less than 16 sec & Never \\
\hline
\end{tabular}

Mrs. Andersson's facially expressed emotions are shown in Table 2. During the first baseline and second intervention observation Mrs. Anderson expressed general alertness "less than 16 seconds". During the first intervention observation she expressed "general alertness" under 16-59 seconds by looking around and turning her body towards the caregiver.

The caregiver's verbal and nonverbal communications during baseline, intervention with humming and follow up are presented in Table 3. The sociable nonverbal variables "faces partner", "sits close to partner", "shows interest", "allows time for the person with dementia to respond" and "tolerate silence" were observed equally during all observations. The 
caregiver made eye contact with Mrs. Andersson during all observations except during the follow up when Mrs. Andersson had her eyes closed for the majority of the time.

Table 3. Verbal and Nonverbal Interaction of Caregiver during two Baseline, two Intervention sessions and one Follow up session (Total score 0-10).

\begin{tabular}{|c|c|c|c|c|c|}
\hline \multicolumn{6}{|c|}{ Caregiver } \\
\hline & Baseline 1 & Baseline 2 & Intervention 1 & Intervention 2 & Follow up \\
\hline Makes eye contact & 10 & 10 & 10 & 10 & 1 \\
\hline Faces partner & 10 & 10 & 10 & 10 & 10 \\
\hline Sits close to partner & 10 & 10 & 10 & 10 & 10 \\
\hline Shows interest & 10 & 10 & 10 & 10 & 10 \\
\hline $\begin{array}{l}\text { Allows time for GR to } \\
\text { respond }\end{array}$ & 1 & 0 & 0 & 0 & 0 \\
\hline Tolerates silence & 10 & 10 & 10 & 10 & 10 \\
\hline Use calm tone of voice & 10 & 10 & 10 & 10 & 10 \\
\hline $\begin{array}{l}\text { Acknowledges emotions } \\
\text { nonverbally }\end{array}$ & 1 & 0 & 0 & 0 & 0 \\
\hline Shows compassion & 5 & 0 & 0 & 0 & 3 \\
\hline Gives broad opening & 1 & 0 & 0 & 0 & 0 \\
\hline Uses partner's name & 1 & 3 & 1 & 2 & 4 \\
\hline Simplifies message & 10 & 0 & 3 & 0 & 7 \\
\hline Asks one question at a time & 6 & 2 & 2 & 2 & 2 \\
\hline Repeats paraphrases & 6 & 0 & 1 & 3 & 0 \\
\hline Open ended questions & 2 & 0 & 2 & 0 & 0 \\
\hline $\begin{array}{l}\text { Uses complex } \\
\text { communication }\end{array}$ & 1 & 0 & 0 & 0 & 0 \\
\hline
\end{tabular}

During the first baseline, the caregiver tried to communicate verbally with Mrs. Andersson by simplifying messages such as, "please swallow", "this is food", and "you have food in your mouth", or by asking one question at a time, such as "Do you want more?”, "Is it hot?” or "Do you want something to drink?”. She even tried to repeat paraphrases in order to communicate with Mrs. Andersson. All of these verbal communications decreased during the other observations.

\section{Summary}

In summary, Mrs. Andersson appeared to eat and drink more during the intervention sessions. Mrs. Andersson appeared slightly the same in her expressions of non-verbal communication. However, she appeared more focused on the food and the caregiver, and in general appeared to be more alert during the interventions. Mrs. Andersson did not make eye contact with the caregiver during any of the observations. At one point during the intervention Mrs. Andersson was humming with the caregiver.

The caregiver's non-verbal communication was the same during all observations. During the first baseline the caregiver verbally communicated about the feeding, and the food. This communication decreased during the other observations.

\section{Discussion}

\subsection{Methodological considerations}

Videotaped observations proved to be a suitable data collection method for this study, as it was considered important to capture Mrs. Andersson's and the caregiver's verbal and non-verbal communication, as well as Mrs. Andersson's 
expressions of emotions. Marshall \& Rossman ${ }^{[31]}$ support this by suggesting that videotaping with audio offers rich information that often exceeds other kinds of data because of its ability to capture both verbal and non-verbal expressions. However, Polit \& Beck ${ }^{[32]}$ point out that when using this data collection method, the researcher should keep in mind that the participants might change their behavior in the knowledge that they are being observed. Mrs. Andersson had severe dementia and did not seem to notice the presence of the video observer. However, it should be kept in mind that the caregiver might have been disturbed by the camera, but this was not expressed by the caregiver said. The video observer was not present in the room during the mealtimes, which prevents the participant from being disrobed by a video observant. Additionally, Latvala, Voukila-Oikkonen, \& Janhonen ${ }^{[33]}$ state that the participants acclimate to the presence of the video camera and start to behave as if they are not being filmed. Although Mrs. Andersson and the caregiver could observe the videotaping equipment, they did not seem to be distracted by it. Another advantage of using video observations is that the video observer was able to capture close-range pictures of Mrs. Andersson and the caregiver in order to study their body movements and facial expressions, which were important for this study.

The research situation chosen for this study was lunch time. However, it is important to keep in mind that if another mealtime situation had been analyzed e.g. breakfast, the results in this study might been different. Also if Mrs. Andersson had been served her favorite food or if she had been served the same food every time, the results might be different. Additionally, the fact that the songs hummed were chosen by the caregiver, and no investigation of what songs Mrs. Andersson preferred was done could have influenced the results if the study. However, we did not see any objective behaviors from Mrs. Andersson when the caregiver hummed.

During the follow up observation, Mrs. Andersson appeared tired, and did eat less than during the other observations. If another day had been chosen results might been different.

The OERS and the Verbal and Nonverbal Interaction scale allowed 10 minutes film to be analyzed, and since the mealtime situations lasted longer than that, what happened after the ten minutes was not analyzed. What we could see when watching the observations in their full length, the remaining time after the ten minutes did not include any extra ordinary that contradicted to the findings of the analysis of the first ten minutes.

To choose a single case design offers the opportunity to elucidate the exact effect of an intervention on the individual level ${ }^{[24]}$, which in this case was accomplished using the OERS and the Verbal and Nonverbal Interaction scale to analyze the recordings. One of the strengths of the design was that Mrs. Andersson, and her caregiver, served as their own controls with two separate baselines, two separate intervention observations, and one follow up session. A single case design does not aim to generalize findings. It would be interesting in further research on the effects of humming during mealtime to include larger samples to allow for generalization.

\subsection{Reflections on the results}

The aim of this study was threefold: to describe expressed emotions in a woman with severe dementia and communication between her and her caregiver without and with the caregiver humming, and to measure food and liquid intake without and with humming. To our knowledge, this is the first study investigating humming during mealtime situations in dementia care. This single case study indicates that humming might have a slight effect upon increasing food and liquid intake, increase positive emotions for a person with dementia, and improve communication between a person with dementia and her caregiver.

The results showed only slight positive effects of the situations with humming. If compared with previous single case studies with MTC ${ }^{[21,22]}$, the result of this study is faint since MTC was shown to radically improve communication ${ }^{[22,23,27]}$ and positive emotions ${ }^{[19,21]}$. The decision to instruct the caregiver to hum instead of sing might have been a disadvantage, since the singing might have been preferable. However, since previous studies of MTC have focused on morning care situations e.g. ${ }^{[17,19,22,23]}$, and this study on mealtime, this cannot be thoroughly discussed. 
The results of this study revealed, however, that Mrs. Andersson ate more during the intervention situations. This was also shown in a study by Ragneskog et al. ${ }^{[15]}$ focusing on eating while listening to music. Maybe the humming could be regarded as music to listen to. Studies focusing on feeding in dementia care ${ }^{[34,35]}$ also argue for the importance of the caregiver's approach during feeding and the need to remain calm and avoid stressing the situation. Studies about singing, and music listening ${ }^{[36,37]}$ argue that music, including singing, has a direct connection to human emotions and memories, and thereby puts us in a certain mood. To sing or listen to songs that we like often relaxes us, makes us emotional or happy. The caregiver in this study was told to hum sing-along songs, children's songs and popular songs from the early part of the 20th century that she enjoyed herself and it is therefore probable that she relaxed during the feeding sessions with Mrs. Andersson. In turn, this might have influenced Mrs. Andersson's appetite and led to her eating more. The caregiver communicated to more or less the same extent during all observations, and asked Mrs. Andersson questions to give her an opportunity to respond with her thoughts and what she wanted. Although we observed only small differences between the baseline situations and the intervention situations, this approach is supported by previous research on caregivers' approach during mealtime, which refers to this as integrity promoted care ${ }^{[38]}$ and claims that the caregiver may influence persons with dementia to eat more. Since the food and liquid intake for Mrs. Andersson did once again decrease during the follow up observations, it could be speculated that the humming might made the caregiver more relaxed and thus, she may also feed Mrs. Andersson in a "smooth temper". Maybe the humming results in improved social interaction between the caregiver and Mrs. Andersson which may influence Mrs. Andersson to eat more. The relation between persons with dementia and the caregiver is central in so called person centered care ${ }^{[39]}$ and acknowledge this in the interaction with persons with dementia are suggested to facilitate communion between caregiver and the person with dementia ${ }^{[40]}$. However, it could also be speculated that Mrs. Andersson on the follow up might had changed in her status or that other components might had influenced her eating and drinking less. This was however nothing that the caregiver did report.

During the intervention Mrs. Andersson appeared to be slightly more active, showed slightly more interest and expressed positive emotions by being generally alert compared to the baseline situations. This has also been found in studies focusing on mealtimes when caregivers use verbal prompting to create a social mealtime environment, and simplify the process of eating ${ }^{[35]}$. This finding is similar to MTC studies, as it has been shown that persons with dementia increase general

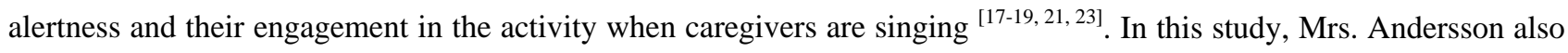
once started to hum along with the caregiver during the intervention sessions similar to findings in previous MTC-studies, e.g. ${ }^{[18,19,23]}$. Humming can be regarded as an expression of pleasure because according to Lawton et al ${ }^{[12,29]}$, and Bigand, Filipic, and Lalitte ${ }^{[4]}$, there is no doubt that emotion is at the core of musical experience, and suggest that basic emotions such as happiness, anger, fear, and sadness can be recognized in, and induced by, musical stimuli.

\section{Conclusion and implications}

One conclusion from this pilot study is that humming does not seem to have the same advantage as MTC during caring situations. However, it should also be concluded that humming in this study might have led to Mrs. Andersson eating more, and being more interested and alert during the mealtime. Since this is a pilot study, and included only one person with dementia and her caregiver, no general conclusions can be drawn. Further studies are needed and should probably include singing, as in MTC, instead of humming or seek to further understand humming during mealtimes with larger samples. Additionally, preferred music should be investigated for the participating persons with dementia to minimize the risk that they do not like the songs hummed or sung by the caregiver.

\section{Acknowledgements and funding}

We wish to thank the caregiver and the person with dementia that participated in this study. We would also like to thank those who financially supported the study; The Knowledge Foundation, Sweden, and Attendo Care, Sweden. 


\section{References}

[1] Ikeda M, Brown J, Holland AJ, Fukuhara R, Hodges JR. Changes in appetite, food preference, and eating habits in frontotemporal dementia and Alzheimer's disease. J Neurol Neurosurg Psychiatry. 2002; 73: 371-6. PMid:50411

http://dx.doi.org/10.1136/jnnp.73.4.371

[2] Watson R, Green SM. Feeding and dementia: a systematic literature review. Journal of Advanced Nursing. 2006 ; 54: 86-93. PMid:16553694 http://dx.doi.org/10.1111/j.1365-2648.2006.03793.x

[3] Kovach CR, Noonan PE, Schlidt AM, Wells T. A model of consequences of need-driven, dementia-compromised behavior. Journal of nursing scholarship: an official publication of Sigma Theta Tau International Honor Society of Nursing. 2005; 37: 134-40.

[4] O'Connor DW, Ames D, Gardner B, King M. Psychosocial treatments of symptoms in dementia: A systematic review of reports meeting quality standards. International Psychogeriatrics. 2009; 21: 225-40. PMid:18814806 http://dx.doi.org/10.1017/S1041610208007588

[5] Hanson LC, Carey TS, Caprio AJ, Lee TJ, Ersek M, Garrett J, et al. Improving decision-making for feeding options in advanced dementia: a randomized, controlled trial. Journal of the American Geriatrics Society. 2011; 59: 2009-16. PMid:22091750 http://dx.doi.org/10.1111/j.1532-5415.2011.03629.x

[6] Small JA, Perry J, Lewis J. Perceptions of family caregivers' psychosocial behavior when communicating with spouses who have Alzheimer's disease. American journal of Alzheimer's disease and other dementias. 2005; 20: 281-9. PMid:16273993 http://dx.doi.org/10.1177/153331750502000510

[7] Vasse E, Vernooij-Dassen M, Spijker A, Rikkert MO, Koopmans R. A systematic review of communication strategies for people with dementia in residential and nursing homes. International psychogeriatrics / IPA. 2009; 29: 1-12.

[8] Azuma T, Bayles KA. Memory impairments underlying language difficulties in dementia. Topics in Language Disorders. 1997; 18: 58-71. http://dx.doi.org/10.1097/00011363-199711000-00007

[9] Skovdahl K, Kihlgren AL, Kihlgren M. Dementia and aggressiveness: video recorded morning care from different care units. Journal of clinical nursing. 2003; 12: 888-98. PMid:14632982 http://dx.doi.org/10.1046/j.1365-2702.2003.00809.x

[10] Christenson AM, Buchanan JA, Houlihan D, Wanzek M. Command use and compliance in staff communication with elderly residents of long-term care facilities. Behav Ther. 2011; 42: 47-58. PMid:21292051 http://dx.doi.org/10.1016/j.beth.2010.07.001

[11] Williams KN, Herman RE. Linking resident behavior to dementia care communication: effects of emotional tone. Behav Ther. 2011; 42: 42-6. PMid:21292050 http://dx.doi.org/10.1016/j.beth.2010.03.003

[12] Lawton MP, Van Haitsma K, Klapper J. Observed affect in nursing home residents with Alzheimer's diseas.e 1996; 51: 3-14.

[13] Guetin S, Soua B, Voiriot G, Picot MC, Herisson C. The effect of music therapy on mood and anxiety-depression: an observational study in institutionalised patients with traumatic brain injury. Annals of physical and rehabilitation medicine. 2009 ; 52: 30-40.

[14] Hulme C, Wright J, Crocker T, Oluboyede Y, House A. Non-pharmacological approaches for dementia that informal carers might try or access: a systematic review. International journal of geriatric psychiatry. 2009; 25: 756-63. PMid:19946870 http://dx.doi.org/10.1002/gps.2429

[15] Ragneskog H, Brane G, Karlsson I, Kihlgren M. Influence of dinner music on food intake and symptoms common in dementia. Scandinavian journal of caring sciences. 1996; 10: 11-7. PMid:8715781

[16] Brown S, Götell E, Ekman S-L. Music-therapeutic caregiving': the necessity of active music-making in clinical care The Arts in Psychotherapy. 2001; 28: 125-35. http://dx.doi.org/10.1016/S0197-4556(00)00085-X

[17] Götell E, Brown S, Ekman SL. The influence of caregiver singing and background music on vocally expressed emotions and moods in dementia care: a qualitative analysis. International journal of nursing studies. 2009; 46: 422-30. PMid:18241869 http://dx.doi.org/10.1016/j.ijnurstu.2007.11.001

[18] Hammar ML, Emami A, Engström G, Götell E. Reactions of Persons with Dementia to Caregivers Singing in Morning Care Situations. The open Nursing Journal. 2010; 4: 35-41.

[19] Hammar ML, Emami A, Götell E, Engström G. The impact of caregivers' singing on expressions of emotions and resistance in persons with dementia during morning care situations: an interventon study. Journal of clinical nursing. 2011; 20: 969-978. PMid:21309873 http://dx.doi.org/10.1111/j.1365-2702.2010.03386.x

[20] Götell E, Brown S, Ekman SL. Influence of caregiver singing and background music on posture, movement, and sensory awareness in dementia care. International psychogeriatrics / IPA. 2003; 15: 411-30.

[21] Hammar ML, Götell E, Engström G. Singing while caring for persons with dementia. Arts \& Health. 2011; 3: 39-50.

[22] Engström G, Hammar Marmstål L, Williams C, Götell E. The impact of singing during caring on a person with dementia- Single Case Analysis of video-recorded sessions. Music and Medicine. 2010; 3: 95-101. 
[23] Hammar ML, Emami A, Engstrom G, Gotell E. Communicating through caregiver singing during morning care situations in dementia care. Scandinavian journal of caring sciences. 2010; 25: 160-168. PMid:20573062 http://dx.doi.org/10.1111/j.1471-6712.2010.00806.x

[24] Kazdin AE. Research design in clinical psychology. 4. uppl. ed. Boston, MA: Allyn and Bacon; 2003.

[25] Folstein MF, Folstein SE, McHugh PR. "Mini-mental state". A practical method for grading the cognitive state of patients for the clinician. Journal of psychiatric research. 1975; 12: 189-98. http://dx.doi.org/10.1016/0022-3956(75)90026-6

[26] Hammar ML, Emami A, Engstrom G, Götell E. Finding the key to communion- Caregivers' experience of 'music therepeutic caregiveing' in dementia care. A qualitative analysis. Dementia: The International Journal of Social research and Practice. 2011; 10: 98-111.

[27] Engström G, Hammar Marmstål L, Williams C, Götell E. Evaluation of communication behavior in persons with dementia during caregivers’ singing. Nursing Reports. 2011. http://dx.doi.org/10.4081/nursrep.2011.e4

[28] Williams C, Parker C. Caregiver conversations with a spouse with AD: Development of an observer rating of communication Issues in Mental Health Nursing. 2012; 33: 244-250.

[29] Lawton MP, Van Haitsma, K., Klapper J.A. Observed Emotion Rating Scale [Internet]. Retrieved 2009-09-09. Available from: www abrahamcenterorg/pri/scaleshtm; 1999.

[30] Lawton MP, Van Haitsma, K., Perkinson, M. \& Ruckdeschel, K. Observed Affect and Quality of Life in Dementia: Further Affirmations and Problems. Journal of Mental Health and Ageing. 1999; 5: 69-81.

[31] Marshall C, Rossman GB. Designing qualitative research. 4. ed. Thousand Oaks, Calif.; London: SAGE; 2006.

[32] Polit DF, Beck CT. Nursing research: generating and assessing evidence for nursing practice. 8. ed. Philadelphia: Wolters Kluwer Health/Lippincott Williams \& Wilkins; 2008.

[33] Latvala E, Voukila-Oikkonen P, Janhonen S. Videotaped recording as a method of participant observation in psychiatric nursing research. Journal of Advanced Nursing. 2000; 31: 1252-1257. PMid:10840260 http://dx.doi.org/10.1046/j.1365-2648.2000.01383.x

[34] Chang CC, Roberts BL. Feeding difficulty in older adults with dementia. Journal of clinical nursing. 2008; 17: 2266-2274. PMid:18705703 http://dx.doi.org/10.1111/j.1365-2702.2007.02275.x

[35] Chang CC, Lin LC. Effects of a feeding skills training programme on nursing assistants and dementia patients. Journal of clinical nursing. 2005; 14: 1185-1192. PMid:16238764 http://dx.doi.org/10.1111/j.1365-2702.2005.01240.x

[36] Fagius J. Hemisfärernas musik. In english: The music of the hemispheres. Göteborg: Bo Ejeby Förlag; 2001.

[37] Zatorre RJ, Chen JL, Penhune VB. When the brain plays music: auditory-motor interactions in music perception and production. 2007; 8: 547-58.

[38] Mamhidir AG, Karlsson I, Norberg A, Kilgren, M. Weight increase in patients with dementia, and alteration in meal routines and meal environment after integrity promoting care. Journal of clinical nursing. 2007; 16: 987-996. PMid:17462050 http://dx.doi.org/10.1111/j.1365-2702.2006.01780.x

[39] Edvardsson D, Winblad B, Sandman, PO. Person-centered care of people with severe dementia diseases and their caregivers. International Psychogeriatrics. 2008; 7: 362-367.

[40] Normann HK, Asplund K, Karlsso S Sandman PO. People with severe dementia exhibit episodes of lucidity. A population based study. Journal of Clinical Nursing. 2006; 14: 1413-1417. PMid:17038102 http://dx.doi.org/10.1111/j.1365-2702.2005.01505.x

[41] Bigand E, Filipic S, Lalitte P. The time course of emotional responses to music. Annals of the New York Academy of Sciences. 2005; 1060: 429-437. PMid:16597797 http://dx.doi.org/10.1196/annals.1360.036 